gistic regression analysis, the strongest predictors for the presence of $C A D$ were waist.hip ratio $\geq 0.85$ (odds ratio $4.08, p=0.001$ ), family history of $C A D$ (odds ratio $3.69, p<0.01$ ) and cigarette smoking (odds ratio 2.81 , $p=0.0 I$ ).

Although the severity of obesity was similar in black women with and without CAD, abdominal obesity was significantly associated with previous myocardial infarction and angiographic evidence of $\mathrm{CAD}$ after adjusting for other CAD risk factors. This finding is consistent with reports in other race/sex groups that abdominal obesity is associated with and highly predictive for the presence of CAD. ${ }^{1,4,5}$ These results have important therapeutic as well as classification implications since interventions such as physical training and associated weight loss may improve metabolic profile and reduce CAD risk to a greater extent in women with abdominal obesity than in those with gluteofemoral obesity. ${ }^{20-22}$ Women with CAD more often had a high school education than those without CAD. This may be due to increased risk in more educated black women, or may indicate that this group was more likely to have their disease diagnosed. Our results differ from those of some investigators who have reported an association between lower levels of education among black women and CAD risk. ${ }^{23}$

An important feature of the current study is that only black women were studied and thus potential confounding effects of race and sex were eliminated. Because only patients with clinically documented myocardial infarction or angiographically documented CAD were included as cases, some subjects with asymptomatic CAD may have been included in the control group. However, if CAD was present in a significant number of control subjects, this should lessen any observed group differences, underestimating the actual difference.

Body fat distribution as measured by the ratio of waist-to-hip circumference is an important risk factor for CAD that is easily determined. Its accuracy for predicting CAD on a prospective basis should be investigated.

1. Manson JE, Colditz GA, Stamfer MJ, Willett WC, Rosner B, Monson RR, Speizer $\mathrm{FE}$, Hennekens CH. A prospective study of obesity and risk of coronary heart dis- ease in women. N Engl J Med 1990;322:882-889.

2. Van Itallie TB. The perils of obesity in middle-aged women. N Engl J Med 1990; 322:928-929.

3. Kumanyika S. Obesity in black women. Epidemiol Rev 1987;9:31-50.

4. Hartz A, Grubb B, Wild R, Van Nort JJ, Kuhn E, Freedman D, Rimm A. The association of waist hip raliu and angiographically determined coronary artery disease. Int J Obes 1990;14:657-665.

5. Donahue RP, Abbott RD, Bloom E, Reed DM, Yano K. Central obesity in coronary heart disease in men. Lancet 1987;1:821-823.

6. Blair D, Habicht JP, Sims EAH, Sylvester D, Abraham S. Evidence for an increased risk for hypertension with centrally located body fat and the effect of race and sex on this risk. Am J Epidemiol 1984;119:526-540.

7. Kaplan NM. The deadly quartet: upper-body obesity, glucose intolerance, hypertriglyceridemia, and hypertension. Arch Intern Med 1989;149:1514-1520.

8. Haffner SM, Stem MP, Hazuda HP, Pugh J, Patterson JK. Do upper-body and centralized adiposity measure different aspects of regional body-fat distribution? Relationship to non-insulin-dependent diabetes mellitus, lipids, and lipoproteins. Diaberes 1987:36:43-51.

9. Ostlund RS, Staten M, Kohrt WM, Schultz J, Malley M. The ratio of waist-to-hip circumference, plasma insulin level, and glucose intolerance as independent predic turs of the $\mathrm{HDL}_{2}$ cholesterol levels in ulder adults. $N$ Engl J Med 1990;322: 229-234. 10. Dawson $D$. Ethnic differences in female overweight: data from the $1985 \mathrm{Na}$ tional Health Interview Survey. Am J Public Health 1988;78:1326-1329.

11. Gillun $R$. Overweight and obesity in black women: a review of published data from the National Center for Health Statistics. J Natl Med Assoc 1987;79:865-871. 12. Dawson DA. Ethnic differences in female overweight: data from the $1985 \mathrm{Na}$ tional Health Inlerview Survey. Am J Public Health 1988;78:1326-1329.

13. Folsom AR, Burke GL, Byers CL, Hutchinson RG, Heiss G, Flack JM, Jacobs DR, Caan B. Implications of obesity for cardiovascular disease in blacks: the CARDIA and ARIC studies. Am J Clin Nutr 1991;53:1604S-1611S.

14. Adams-Campbell LL, Nwankwo M, Ukoli F, Omene J, Haile GT, Kuller LH Body fat distribution patterns and blood pressure in black and white women. $J$ Natl Med Assoc 1990;82:573-576.

15. Svec F, Rivera $M$, Huth $M$. Correlation of waist to hips ratio to the prevalence of diabetes and hypertension in black females. J Natl Med Assoc 1990;82:257-261. 16. Gillum RF. The association of body fat distribution with hypertension, hypertensive heart disease, coronary heart disease, diabetes, and cardiovascular risk factors in men and women aged 18-79 years. $J$ Chron Dis 1987;40:421-428.

17. Gillum RF, Cardiovascular disease in the United States; an epidemiolugic overview. In: Saunders E, ed. Cardiovascular Diseases in Blacks. Philadelphia: FA Davis, 1991:3-16.

18. Ashwell M, Chin S, Stalley S, Ganrow JS. Female fat distribution-a simple classification based on two circumference measurements. Int J Obes 1982;6: 143-152. 19. Dumin JVGA, Womersley J. Body fat assessed from total body density and its estimation from skinfold thickness: measurements of 481 mien ard women aged 16-72 years. Br J Nutr 1974;32;77-97.

20. Krotiewski M. Can body fat patteming be changed? Acta Med Scand Suppl 1988; 723:213-223.

21. Depres JP, Tremblay A, Nadeau A, Bouchard C. Physical training and changes in regional adipose tissue distribution. Acta Med Scand Suppl 1988;723:205-212. 22. Tremblay A, Depres JP, Bouchard C. Alteration in body fat and body fat distribution with exercise. In: Bouchard C, Johnston FE, eds. Fat Distribution During Growth and Later Health Outcomes. New York: Alan R. Liss, 1988:297-312. 23. Keil JE, Sutherland SE, Knapp RG, Lackland DT, Gazes PC, Tyroler HA. Mor tality rates and risk factors for coronary disease in black as compared with white men and women. $N$ Engl $J$ Med 1993;329:73-78.

\title{
Akinesis Becoming Dyskinesis During High-Dose Dobutamine Stress Echocardiography: A Marker of Myocardial Ischemia or a Mechanical Phenomenon?
}

Mariarosaria Arnese, MD, Paolo M. Fioretti, MD, Jan H. Cornel, MD, Joyce Postma-Tjoa, BSc, Ambroos E. M. Reijs, MSc, and Jos R. T. C. Roelandt, MD

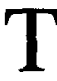
here is increasing evidence that dobutamine stress echocardiography is a potentially useful clinical technique for assessing the functional severity of coronary

From the Thoraxcenter and Department of Nuclear Medicine, University Hospital Rotterdam Dijkzigt, Erasmus University, Rotterdam, the Netherlands. Dr. Amese is supported by a fellowship grant of the Società Italiana di Cardiologia, Rome, Italy. Dr. Fioretti's current address is: Thoraxcenter, Ba 300, Academisch Ziekenhuis Rotterdam, Dr Molewaterplein 40, 3015 GD Rotterdam, the Netherlands. Manuscript received April 16, 1993; revised manuscript received August 9, 1993, and accepted August 10. disease and myocardial viability. ${ }^{1-8}$ Therefore, it has been suggested that dobutamine stress echocardiography provides a unique opportunity to assess with 1 easily repeatable, inexpensive and widely available method both residual ischemia and viability. ${ }^{5}$ Several studies, including some from our group, ${ }^{9-12}$ have confirmed a fair agreement between stress echocardiography with different stress modalities and perfusion scintigraphy for the diagnosis of myocardial ischemia. The specific aim of the present study was to distinguish whether the pathophysiologic mechanism of an equivocal stress echocar- 
TABLE I Demographic, Electrocardiographic, Echocardiographic and Scintigraphic Results

\begin{tabular}{|c|c|c|c|c|c|c|c|c|c|c|c|}
\hline Patient & $\begin{array}{c}\text { Age } \\
\text { (yr) } \\
\& \text { Sex }\end{array}$ & $E C G$ & Dobutamine & Atropine & Max HR & Max BP & Dyskinesis & SPECT & $\mathrm{ChP}$ & ST & $\begin{array}{c}\text { Side } \\
\text { Effects }\end{array}$ \\
\hline 1 & $24 \mathrm{~F}$ & Sept & 40 & + & 160 & $105 / 50$ & Apic & Apic & 0 & $\uparrow$ & 0 \\
\hline 2 & $42 \mathrm{~F}$ & Ant & 40 & 0 & 145 & $155 / 105$ & Sept-apic & Apic & 0 & $\uparrow$ & 0 \\
\hline 3 & $44 \mathrm{M}$ & $\operatorname{lnf}$ & 40 & + & 148 & $150 / 80$ & $\operatorname{lnf}$ & Post & 0 & $=$ & PVCs \\
\hline 4 & $44 \mathrm{M}$ & Ant & 40 & 0 & 150 & $140 / 70$ & Apic & Apic & 0 & $\downarrow$ & PVCs \\
\hline 5 & $47 \mathrm{M}$ & Ant & 30 & 0 & 134 & $120 / 60$ & Apic & Apic & + & $\uparrow$ & 0 \\
\hline 6 & $51 \mathrm{M}$ & Ant & 40 & + & 120 & $120 / 75$ & Apic & Apic & 0 & $=$ & 0 \\
\hline 7 & $54 \mathrm{M}$ & $\operatorname{Inf}$ & 40 & + & 118 & $120 / 80$ & $\ln f$ & Post & 0 & $=$ & 0 \\
\hline 8 & $57 \mathrm{M}$ & Ant & 40 & + & 141 & $120 / 60$ & Apic & Apic & 0 & $=$ & 0 \\
\hline 9 & $58 \mathrm{M}$ & Ant & 40 & + & 95 & $90 / 50$ & Apic & Apic & 0 & $=$ & VTs \\
\hline 10 & $61 \mathrm{M}$ & $\operatorname{Inf}$ & 40 & 0 & 90 & $80 / 60$ & $\operatorname{lnf}$ & Post & 0 & $=$ & Hypo \\
\hline 11 & $63 \mathrm{~F}$ & $\operatorname{Inf}$ & 40 & + & 108 & $140 / 75$ & $\ln f$ & Post & 0 & $=$ & 0 \\
\hline 12 & $64 \mathrm{M}$ & $\ln f$ & 40 & + & 140 & $145 / 75$ & $\ln f$ & Post & 0 & $=$ & 0 \\
\hline 13 & $65 \mathrm{M}$ & Sept & 40 & 0 & 150 & $110 / 70$ & Sept-apic & Apic & + & $\downarrow$ & 0 \\
\hline 14 & $65 \mathrm{M}$ & Ant & 30 & 0 & 150 & $150 / 70$ & Sept & Sept & + & $\downarrow$ & 0 \\
\hline 15 & $66 \mathrm{M}$ & Ant & 40 & 0 & 138 & $150 / 80$ & Apic & Apic & 0 & $\downarrow$ & $A F$ \\
\hline 16 & $66 \mathrm{M}$ & Ant & 40 & 0 & 133 & $130 / 70$ & Apic & Apic & 0 & $=$ & 0 \\
\hline 17 & $67 F$ & Ant & 40 & 0 & 120 & $140 / 70$ & Ant & Ant & 0 & $\uparrow$ & 0 \\
\hline 18 & $68 \mathrm{~F}$ & $\operatorname{lnf}$ & 40 & + & 110 & $170 / 90$ & $\operatorname{lnf}$ & Post & 0 & $=$ & VTns \\
\hline 19 & $73 \mathrm{M}$ & Sept & 40 & 0 & 133 & $175 / 85$ & Apic & Apic & 0 & $\uparrow$ & 0 \\
\hline 20 & $80 \mathrm{M}$ & $\ln f$ & 40 & + & 135 & $120 / 60$ & $\ln f$ & Post & 0 & $=$ & $\mathrm{AF}$ \\
\hline
\end{tabular}

diocardiographic finding, that of an akinetic segment at rest becoming dyskinetic during peak dobutamine testing, was due to ischemia or was a nonischemic mechanical event. This is a particularly important clinical topic because correct identification of viable and jeopardized myocardium is crucial for the proper selection of coronary revascularization in patients with left ventricular dysfunction. Therefore, 20 patients with this pattern (an akinetic segment at rest becoming dyskinetic during peak dobutamine stress testing) were studied with simultaneous, 2-stage (low- and high-dose) dobutamine stress echocardiography and perfusion single-photon emission computed tomography (SPECT).

The study group comprised 20 of 560 consecutive patients (15 men and 5 women; mean age 58 years, range 24 to 80) referred for dobutamine stress echocardiography for the diagnosis or functional assessment of coronary disease. All patients had a previous myocardial infarction and regional akinesia on resting echocardiography becoming clearly dyskinetic during a highdose dobutamine-atropine test. At the time of the study, patients were not receiving $\beta$ blockers. All patients were studied by simultaneous echocardiography and technetium-99m isonitrile $(n=16)$ or thallium-201 SPECT ( $n=4)$ during infusion of dobutamine-atropine.

The test was performed as previously described ${ }^{3,8,12}$ Briefly, a 2-dimensional echocardiogram was recorded at baseline using a commercially available, wide-angle, phased-array system (Esaote Biomedica SIM 7000 CFM or Vingmed CFM 800). The following views were obtained for subsequent analysis: apical 4-, 3-, 2- and 5chamber. The left ventricle was divided into 14 segments, and each segment was scored using a 4-point scale: $l=$ normal wall motion and thickening; $2=$ hypokinesia; 3 = akinesia (absence of systolic wall motion and thickening); and 4 = dyskinesia (systolic outward wall motion with thinning).

Following a previously described protocol, ${ }^{3}$ dobutamine was infused through an antecubital vein cannula beginning at the dose of $10 \mu \mathrm{g} / \mathrm{kg} / \mathrm{min}$ and increasing by $10 \mu \mathrm{g} / \mathrm{kg}$ every 3 minutes up to a maximum of 40 $\mu \mathrm{g} / \mathrm{kg} / \mathrm{min}$, which was continued for 6 minutes. In patients without side effects, myocardial ischemia or $85 \%$ of age predicted maximal heart rate, atropine (up to 1 mg intravenously) was added. Two-dimensional echocardiography was continuously monitored and recorded on videotape for the last minute of each stage, and continuously after administration of atropine. The images were digitized and displayed side by side on a quadscreen for comparison of rest and stress images. To analyze wall motion, the images recorded on videotape were subsequently reviewed at various playback speeds also. Echocardiographic images were analyzed by 2 independent observers who were unaware of the clinical data of the individual patient. Dobutamine stress echocardiography was considered "positive" when a new wall motion abnormality or a worsening of abnormal wall motion (inward motion or thickening, or both) appeared in $\geq 1$ segments at peak stress.

Technetium $-99 \mathrm{~m}$ isonitrile $(370 \mathrm{MBq})$ or thallium$201(80 \mathrm{MBq})$ was injected intravenously 1 minute before termination of the stress test. Post-stress SPECT imaging was obtained 1 hour after administration of technetium and $\leq 10$ minutes after thallium. Resting technetium-99m isonitrile SPECT was repeated on a separate day, whereas 4-hour redistribution thallium imaging was repeated after a reinjection of $40 \mathrm{MBq}$. For each patient, 6 short-axis and 3 vertical long-axis slices were displayed and analyzed. As previously described, the left ventricle was divided in 47 segments, and each segment 
was scored with a 4-point scale (from $1=$ normal to 4 = "absence" of uptake). ${ }^{10,12}$ Visual analysis was performed by 2 observers with the assistance of circumferential profile analysis of the short-axis slices. The apical portion was assessed only visually.

Three different responses were defined: "normal," "ischemia" (transient perfusion defects), and "infarction" (fixed perfusion defect). The severity of ischemia and infarction was graded as mild, moderate and severe.

Demographic and clinical data, and the results of simultaneous dobutamine stress echocardiography and perfusion SPECT in the 20 patients are summarized in Table I.

In all patients, there was agreement between the sites of the akinetic region on the resting echocardiogram and of perfusion defects on the resting or redistribution SPECT images. Furthermore, the electrocardiographic site of the infarction was in all cases consistent with the imaging results.

The dobutamine stress test was uncomplicated in all cases. The highest dose was $40 \mu \mathrm{g} / \mathrm{kg} / \mathrm{min}$ in 18 patients (with atropine added in 10). The target heart rate was achieved in 10 patients. In 6 patients, the target heart rate was not achieved despite the full dose of dobutamine and atropine, and in 4, the test was stopped because of: (1) hypotension $(n=1)$, or (2) electrocardiographic changes $(n=3)$. Chest pain occurred in 3 patients, $S T$ segment depression in 4, and ST-segment elevation in 5.

By definition, all patients developed a worsening of the akinetic region (which became dyskinetic), whereas new wall motion abnormalities remote to the akinesia became apparent in 8 cases. The wall motion of the akinetic segment that became dyskinetic at peak stress did not improve with low-dose dobutamine. In contrast, the wall motion of the control left ventricular regions improved in all cases, which confirms the adequacy of lowdose dobutamine for improving the contractility of normal myocardium. Myocardial scintigraphy showed a severe fixed perfusion defect in all akinetic regions that became dyskinetic at peak stress, which is consistent with an absence of scintigraphic markers of ischemia in those regions.

Dobutamine stress echocardiography is a rapidly developing noninvasive technique for assessing patients with coronary artery disease. However, more study is needed for the pathophysiologic interpretation of some specific stress echocardiographic patterns. In this regard, myocardial perfusion scintigraphy, performed simultaneously with stress echocardiography, provides a unique opportunity for the validation of stress echocardiographic findings. ${ }^{9-12}$

The classic marker of myocardial ischemia by stress echocardiography is the appearance of new wall motion abnormalities at peak stress, whereas an improvement of wall motion (including wall thickening) of a severely hypokinetic or akinetic segment during low-dose dobutamine is considered a marker of residual viable myocardium. 5,6

Therefore, the evaluation of dobutamine stress echocardiography in 2 phases (low and high doses) enables a more complete and comprehensive evaluation, particularly in patients with left ventricular dysfunction who represent an increasing proportion of patients in our daily practice.

The interpretation of stress echocardiography for the detection of myocardial ischemia is easiest in patients with normal or moderate hypokinesia on resting echocardiography, but is increasingly difficult in those with previous myocardial infarction and severe hypo- or akinesia at rest. The main concern in these cases is whether the worsening of akinesia, becoming dyskinesia during stress, represents myocardial ischemia or is mainly a mechanical phenomenon due to a systolic outward bulging secondary to a hyperdynamic contraction of the remaining myocardium. The concepts of stunned and hibernating myocardium, which may be viable but not contractile at rest, ${ }^{5,6}$ make this an important issue.

The main finding of this study, in which we used simultaneous perfusion scintigraphy as a standard for comparison with stress echocardiography, is that the scintigraphic equivalent of an akinetic segment, becoming dyskinetic during peak stress without an improvement in wall thickening during low-dose dobutamine, is that of a severe and fixed perfusion defect. This is consistent with the presence of an infarcted tissue without significant ischemia in that territory. If we accept perfusion scintigraphy as an adequate "gold standard" for the diagnosis of myocardial ischemia, the data suggest that the assessment of dobutamine stress echocardiography in 2 stages is useful to clarify this stress echocardiographic pattern.

This study would be more complete if we had included patients in whom an improvement in wall thickening occurred during low-dose dobutamine to assess the frequency of stress-induced ischemia. Another potential limitation of the study is that the radiotracer used was different in different patients, because technetium$99 \mathrm{~m}$ isonitrile was used in 16 cases and thallium in 4 . It is very unlikely that the conclusions of the study were influenced by this methodologic problem, since in previous studies, little disagreement was found between stress/rest technetium- $99 \mathrm{~m}$ isonitrile and thallium studies for the detection of myocardial ischemia. ${ }^{13}$

In summary, by combining dobutamine stress echocardiography and perfusion scintigraphy, we conclude that in the case of no improvement in wall thickening with low-dose dobutamine, the echocardiographic pattern of an akinetic segment at rest becoming dyskinetic during peak stress does not represent myocardial ischemia and is probably related to a mechanical phenomenon due to a hypercontraction of the surrounding myocardium.

1. Berthe C, Pierard A, Hiernaux M, Trotteur G, Lempereur P, Carlier J, Kulbertus $\mathrm{HE}$. Predicting the extent and location of coronary artery disease in acute myocardial infarction by echocardiography during dobutamine infusion. Am J Cardiol 1986;58:1167-1172.

2. Sawada SG, Segar DS, Ryan T, Brown SE, Dohan AM, Williams R, Fineberg NS, Armstrong WF, Feigenbaum H. Echocardiographic detection of coronary artery disease during dobutamine infusion. Circulation 1991;83:1605-1614.

3. McNeill AJ, Fioretti PM, El-Said EM, Salustri A, De Feyter PJ, Roelandt JRTC Dobutamine stress echocardiography before and after coronary angioplasty. Am J Cardiol 1992;69:740-745.

4. Akosah KO, Porter TR, Simon R, Funai JT, Minisi AJ, Mohanty PK. Ischemiainduced regional wall motion abnormality is improved after coronary angioplasty: 
demonstration by dobutamine stress echocardiography. I Am Coll Cardiol 1993;21: 584-589.

5. Piérard LA, De Landsheere CM, Berthe C, Rigo P, Kulbertus IIE. Identification of viable myocardium by echocardiography during dobutamine infusion in patient with myocardial infarction after thrombolytic therapy: comparison with positron emission tomugraphy. J Am Coll Cardiol 1990;15:1021-1031.

6. Marzullo P, Parodi O, Reisenhofer B, Sambuceti G, Picano E, Distante A, Gimell A, L'Abbate A. Value of rest thallium-201/technetium- $99 \mathrm{~m}$ sestamibi scans and dobutamine echocardiography for detecting myocardial viability. Am $J$ Cardiol 1993:71:166-172.

7. Mazeika PK, Nadazdin A, Oakley CM. Prognostic value of dobutamine echocardiography in patients with high pretest likelihood of coronary artery disease. Am J Cardiol 1993:71:33-39.

8. Poldermans D, Fioretti PM, Forster T, Thomson IR, Boersma E, El-Said EM du Buis NAJJ, Ruelandl JRTC, varı Urk H. Dobuldimine stress echocardiography for assessment of perioperative cardiac risk in patients undergoing major vascular surgery. Circulation 1993;87:1506-1512.

9. Marwick TH, Nemec JJ, Stewart WJ, Salcedo EE. Diagnosis of coronary artery disease using exercise echocardiography and positron emission tomography: comparison and analysis of discrepant results. J Am Soc Echocardiogr 1992;5;231-238 10. Pozzoli MMA, Fioretti PM, Salustri A, Reijs AEM, Roelandt JRTC. Exercise echocardiography and technetium- $99 \mathrm{~m} \mathrm{MIBI}$ single-photon emission computed tomography in the detection of coronary artery disease. Am J Cardiol 1991;67 350-355.

11. Quinoñes MA, Verani MS, Haichin RM, Mahmarian JJ, Suarez J, Zoghbi WA. Exercise echocardiography versus 201-Tl single-photon emission computed tomography in evaluation of coronary artery disease. Analysis of 292 patients. Circulation 1992:85:1026-1031.

12. Forster T, McNeill AJ, Salustri A, Reijs AEM, El-Said EM, Roelandt JRTC, Fiorelli PM. Simultaneous dobutamine stress echocardiography and technetium$99 \mathrm{~m}$ isonitrile single-photon emission computed tomography in patients with suspected coronary artery disease. $J$ Am Coll Cardiol 1993;21:1591-1596.

13. Iskandriaı AS, Heo J, Koing B, Lyons E, Marsch S. Use of technetium-99m isonitrile (RP-30A) in assessing left ventricular perfusion and function at rest and during exercise in coronary artery disease, and comparison with coronary arteriography and exercise thallium-201 SPECT inaging. Am J Cardiol 1989;64:270-275.

\title{
Utility of Rapid Percutaneous Cardiopulmonary Bypass for Refractory Hemodynamic Collapse in the Cardiac Catheterization Laboratory
}

\author{
Joseph Redle, MD, Blair King, CCP, Gerald Lemole, MD, and Andrew J. Doorey, MD
}

$\mathrm{P}$ ercutaneous cardiopulmonary bypass (PCB) has been found to be effective in refractory hemodynamic collapse in certain circumstances. ${ }^{1-6}$ The successful reversal of such collapse by PCB is almost exclusively limited to the cardiac catheterization laboratory and cardiovascular surgical intensive care units. ${ }^{1-6}$ Probably these areas are best suited for quick insertion of PCB because of the proximity of the equipment and experienced personnel, since the time taken to institute PCB is inversely correlated with the probability of a successful outcome. . $^{2,5}$ Insofar as the "correctability" of the precipitating disorder is also associated with a higher success rate, the catheterization laboratory may be an optimal place to use emergency PCB, because of the ability to often define and correct the disease process. 5 Nonetheless, the role of emergency PCB in patients who develop hemodynamic instability in the catheterization

From the Departments of Medicine and Cardiac Surgery, Medical Center of Delaware and Jefferson Medical College of Thomas Jefferson University, 4745 Ogletown-Stanton Road, Suite 220, Newark, DE 19713. Manuscript received June 4, 1993: revised manuscript received and accepted September 8, 1993. laboratory has not been fully defined. ${ }^{5}$ We investigated patients brought into the catheterization laboratory under stable conditions in whom refractory hemodynamic collapse occurred during either diagnostic or interventional procedures.

From October 1989 to September 1992, 21 patients were put on $P C B$ in the catheterization laboratory: 4 patients went on $P C B$ prophylactically, 4 others had hemodynamic collapse outside of the catheterization laboratory, and 2 others were put on PCB as a "bridge" to the operating room in the setting of myocardial ischemia but in the absence of hemodynamic collapse. The remaining 11 patients with refractory hemodynamic collapse developing in the catheterization laboratory during diagnostic or interventional procedures form the basis of this report (Table I). Five patients survived to hospital discharge. Eight of the 11 patients were stabilized and transferred to the operating room for coronary bypass grafting or valve replacement. Four of these 8 survived to discharge. Of the 3 patients not sent to the operating room, all had successful coronary angioplasty after stabilization by $P C B$, and 1 survived. Despite the preceding refractory hemodynamic collapse, only 1 of

\begin{tabular}{|c|c|c|c|c|c|c|}
\hline Patient & Reason & OR & $\begin{array}{l}\text { Time of First } \\
\text { Instability } \\
\text { to PCB (min) }\end{array}$ & $\begin{array}{l}\text { Time of PCB } \\
\text { Decision } \\
\text { to PCB (min) }\end{array}$ & $\begin{array}{c}\text { Weaned Off } \\
\text { Bypass }\end{array}$ & $\begin{array}{c}\text { Hospital } \\
\text { Discharge }\end{array}$ \\
\hline 1 & PTCA & + & 55 & 7 & + & + \\
\hline 2 & PTCA & 0 & 40 & 21 & + & 0 \\
\hline 3 & CAD \& AS & + & 57 & 9 & + & 0 \\
\hline 4 & AS & + & 57 & 19 & + & 0 \\
\hline 5 & PTCA & 0 & 33 & 8 & + & + \\
\hline 6 & CAD & + & 30 & 18 & + & 0 \\
\hline 7 & PTCA & + & 31 & 12 & + & + \\
\hline 8 & PTCA & 0 & 59 & 16 & 0 & 0 \\
\hline 9 & PTCA & + & 62 & 15 & + & 0 \\
\hline 10 & PTCA & + & 10 & 10 & + & + \\
\hline 11 & PTCA & + & 20 & 10 & + & + \\
\hline
\end{tabular}

